\title{
Electro-osmotic Consolidation Experiments for Improvement of Soft Soils of Sarawak
}

\author{
J.H.S. Yee ${ }^{1}$ and Shenbaga R. Kaniraj ${ }^{2}$ \\ ${ }^{1}$ PhD Student, School of Engineering and Science, Curtin University of Technology, CDT 250, 98009, \\ Miri, Sarawak, Malaysia; sharon.yee@stud.curtin.edu.my \\ ${ }^{2}$ Professor, Research and Development, Curtin University of Technology, CDT 250, 98009, Miri, \\ Sarawak, Malaysia; kaniraj@curtin.edu.my
}

\begin{abstract}
An important priority for the Sarawak State of Malaysia is of providing road networks to enhance connectivity and economic development throughout the State. However, the more populated coastal areas along the South China Sea are covered by peat and other soft soil deposits. Construction of roads in such areas requires extensive ground improvement by preloading that is time consuming and at times also expensive. Electro-osmotic consolidation is a well known ground improvement technique for improvement of fine grained soft soils where a direct current introduced into the soil induces electro-osmotic flow of water from the anode to the cathode. Experiments were carried out in the laboratory to study the feasibility of electro-osmotic consolidation of an organic soil sample from North Sarawak. Commercially available prefabricated electric vertical drains were used as electrodes. This paper presents the experimental set-up, geotechnical characterization of the soil sample and the results of the tests conducted with incremental voltage gradient. Voltage and current were measured to assess the power consumption. The water content decreased and the shear strength increased significantly after 8 days of electrokinetic treatment. The results indicated a good potential for the application of electro-osmotic consolidation in organic soils.
\end{abstract}

\section{INTRODUCTION}

Sarawak is the largest and a fast developing State in Malaysia. A good road network is essential for the economic development of the State. However, construction of roads is often hindered by peat and other problematic soft soils found in Sarawak. The common method of treating such problematic soils is by preloading the soil to induce significant primary consolidation and even secondary compression of the soil before the beginning of construction so that post construction settlement can be kept to a minimum. Some of the difficulties with the preloading treatment method are the long treatment period, non-availability of preload material, and transportation costs for importing and removal of the preload material. 


\section{OBJECTIVE OF STUDY}

Electro-osmotic consolidation studies on peat or organic soils are, very few. The present study is intended to add to the limited knowledge available on electro-osmotic consolidation of organic soils. Laboratory tests were carried out to study the influence of incremental voltage gradient on the electro-osmotic consolidation of an organic soil collected from Sarawak. Commercially available prefabricated electric vertical drain (EVD) was used as electrodes. Changes in water content and shear strength due to electro-osmotic consolidation were measured. The settlement of the soft organic soil beds and discharge of water were monitored during the experiment. Voltage and current were also recorded to estimate the power consumption.

\section{BACKGROUND}

Electro-osmosis in soils is the movement of pore water in an electrical field induced by the application of direct current. Positively charged electrodes (anode) and negatively charged electrodes (cathode) inserted into a saturated soil create an electrical field between them. The positively charged ions in the pore water migrate towards the cathode and drag the free water molecules in the pore water along with them, while the negatively charged ions are attracted to the anode.

In electro-osmotic consolidation, the rate of flow of water, $\mathrm{Q}$, is expressed as:

$$
Q=k_{p} t_{R} A
$$

In Eq $1, k_{\mathrm{e}}$ is the coefficient of electro-osmotic permeability $\left(\mathrm{m}^{2} / \mathrm{Vs}\right), i_{\mathrm{e}}$ is the applied voltage gradient $(\mathrm{V} / \mathrm{m})$ and $A$ is the area of flow $\left(\mathrm{m}^{2}\right)$. Equation 1 is similar to Darcy's Law for hydraulic flow in primary consolidation by dissipation of excess pore water pressure. Although analogous with Darcy's Law, the electro-osmotic coefficient of permeability, $k_{e}$, differs from the hydraulic coefficient of permeability, $k_{\mathrm{h}}$, in that $k_{e}$ is not dependent on pore size. Studies have shown that electro-osmotic permeability for fine-grained soils can be of a magnitude reaching four orders greater when compared to hydraulic permeability (Glendinning et al 2008). The $k_{e}$ value of soils suitable for electro-osmotic treatment is typically about $10^{-9} \mathrm{~m}^{2} / \mathrm{sV}$ and $k_{h}$ is in the range of $10^{-10}$ and $10^{-8} \mathrm{~m} / \mathrm{s}$ (Shang 1998).

The conventional electrodes used in electrokinetic treatment are made of aluminium, copper or steel which would corrode due to the electrochemical reactions that occurs during application of electric current. Reduction at the anode induces an acid front in the vicinity of the anode, leading to corrosion of the electrodes. The deterioration of the electrodes decreases the soil-electrode contact area, resulting in loss of efficiency of the electrokinetic process. Electrically conductive polymeric electrodes namely electrokinetic geosynthetics (EKG) which are less corrodible and are capable of producing results comparable to conventional electrode have been developed recently and used in a number of studies on soft clays, mine tailings and sludges (Hamir et al 2001, Fourie et al 2007, Glendinning et al 2007 \& 2008). 
In South East Asia, several laboratory studies and field trials of electro-osmotic consolidation have been carried out on Bangkok and Singapore clays. These studies have reported considerable gain in the shear strength of the treated clays (Bergado et al 2000 \& 2003, Chew et al 2004, Rittirong et al 2008). Kaniraj and Huong (2008 \& 2009) reported a good potential for the electro-osmotic consolidation of a peat sample from North Sarawak.

\section{EXPERIMENTAL METHODOLOGY}

\section{Soil Specimen}

An organic soil collected from Sibu in the Sarawak State was used in the experiments. The organic content, $N$, of the soil was $49 \%$ and the natural water content was $86 \%$. The Atterberg limits of the soil were, liquid limit $w_{l}=245 \%$, plastic limit $w_{p}=155 \%$ and plasticity index $P I=90 \%$.

\section{Experimental Set-up}

Containers open at the top and made of glass with internal dimensions of $\mathrm{L}: \mathrm{B}: \mathrm{H}=$ 250:110:250mm were used for the preparation of test beds. The prefabricated EVD was $100 \mathrm{~mm}$ wide and $5.5 \mathrm{~mm}$ thick and comprised of a thin copper sheet encased between two sheets of serrated electrically conductive polymeric material. This copper-polymer sandwich was sheathed by a geosynthetic filter. Strips, $15 \mathrm{~mm}$ wide and $240 \mathrm{~mm}$ long, were cut from the full width EVD and wrapped in geotextile filter. The strips were used as anodes and cathodes to simulate three dimensional electroosmotic consolidation flow of water in the test beds. The drainage well to collect the drained water was made of a $20 \mathrm{~mm}$ outer diameter perforated PVC pipe wrapped in geotextile filter. Since the water drained out only at the cathode end in the electroosmotic consolidation tests, the drainage pipe was installed at only one end of the test bed. Figure 1 shows the plan of the experimental set up.

\section{General Experimental Procedure}

The experiment was carried out according to the following procedure.

Large size wood pieces and roots were removed from the organic soil sample to obtain more uniform test beds in all test tanks. The soil was mixed with water in a planetary mixer to a slurry consistency. The mixing process was repeated until the required quantity of slurry was obtained. The mixed soil slurry was kept in a large container and was thoroughly mixed again to make the water content of the whole slurry uniform.

The $15 \mathrm{~mm}$ width and $240 \mathrm{~mm}$ height strips of EVD cut from the prefabricated EVD were wrapped in geotextile filter. The $20 \mathrm{~mm}$ outer diameter and $230 \mathrm{~mm}$ height perforated PVC pipe was wrapped in geotextile filter. It was used as drainage well where the water collected would be pumped out at pre-determined intervals. 


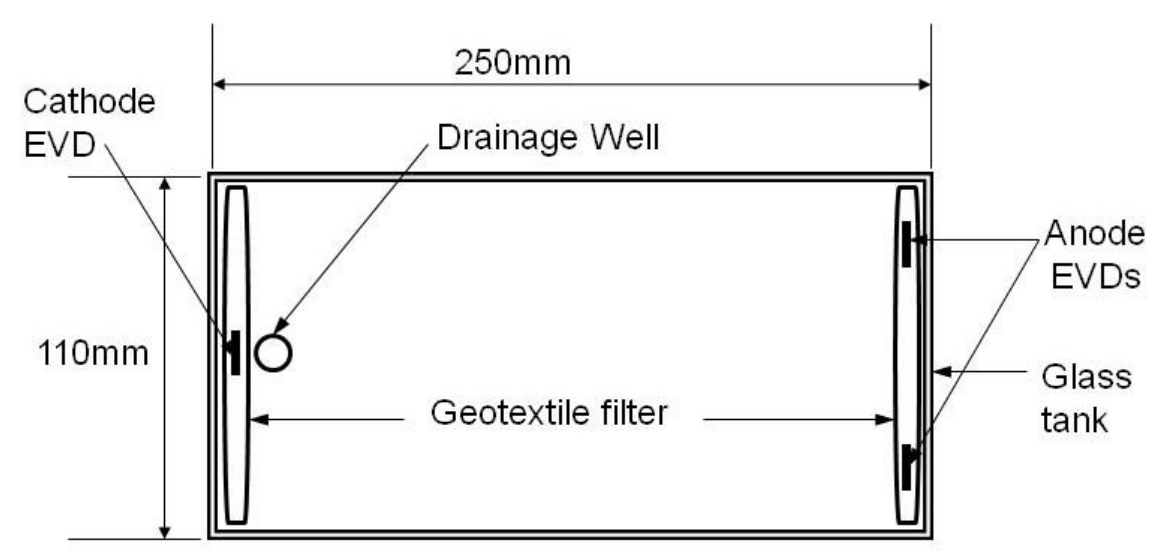

FIG. 1. Plan of electro-osmotic consolidation experimental set up

The EVDs were immersed in water and then placed at each end of the tank. A 2anodes-1cathode configuration was used for the electro-osmotic consolidation as shown in Figure 1. The EVDs were placed in this manner to create a more uniform electric field in the test bed and to produce three dimensional osmotic flow conditions. The drainage well was placed only at the cathode end because water flowed only towards the cathode (Kaniraj and Huong 2008). The prepared soil slurry was then placed in the tank in small thickness layers until a height of about $200 \mathrm{~mm}$ was achieved. Each layer was tamped with a wooden bar to remove the trapped air. Initial water content was determined and vane shear tests were carried out at 2 locations at the top of the test bed. Discrete $10 \mathrm{~mm}$ square glass plates were placed at the top along the length of the test bed for measurement of settlement. The settlement measurements were made at $24 \mathrm{~h}$ intervals using digital vernier caliper.

One test bed was used for self weight consolidation test. This was a control test in which no electric current was applied, $i_{e}=0 \mathrm{~V} / \mathrm{m}$. The preparation of this test bed and the position of the drainage well were similar to those for the electro-osmotic consolidation test beds. As no voltage gradient was applied, EVDs were not used in the self weight consolidation test beds. Water was pumped out from the drainage well at intervals of $6 \mathrm{~h}$ during the day and $12 \mathrm{~h}$ overnight. The self weight consolidation test was stopped at the end of the 8th day.

The electro-osmotic consolidation test was carried out in another test bed. In this test bed, voltage gradient was applied in $10 \mathrm{~V} / \mathrm{m}$ increments daily starting with an initial voltage gradient of $10 \mathrm{~V} / \mathrm{m}$ on the first day and ending with a voltage gradient of $80 \mathrm{~V} / \mathrm{m}$ on the 8 th day. The rate of electro-osmosis flow became very small after 8 days. Prolonged treatment increased energy consumption without a concomitant strength improvement. Therefore, the test was stopped at the end of 8th day. In this test, water was pumped out from the drainage well at 3 hour intervals during the day to prevent water from filling up the drainage well or getting trapped at the cathode end and to minimize the possibility of reduction in the efficiency of water removal. 
After the self weight and electro-osmotic consolidation tests were completed, vane shear tests were carried out at three different locations at the top of the test beds. Shelby tubes were inserted to extract soil from three different locations in the test beds for determination of vane shear strength at the bottom of the test bed. The soil in the Shelby tubes was then extruded, divided into segments, and the water content of each segment was determined.

\section{EXPERIMENTAL RESULTS}

\section{Settlement Profile}

Figure 2 shows the surface profiles of the test beds for self weight consolidation and electro-osmotic consolidation tests. The curve $t=0$ shows the initial surface profile and the curve $t=8$ days shows the surface profile at the end of consolidation. SW and EO stand for self weight consolidation and electro-osmotic consolidation, respectively. Comparison of the two surface profiles at the start and end of the tests clearly indicates that electro-osmotic consolidation induced a higher settlement at a faster settlement rate.

In the self weight consolidation test, a total volume of about $185 \mathrm{ml}$ was pumped out from the drainage well. In the same time period of 8 days, the electro-osmotic consolidation yielded a total volume of $1083 \mathrm{ml}$. In other words, electro-osmotic consolidation caused a $485 \%$ increase in the drained volume of water. Figure 3 shows the variation of total flow of water with time.

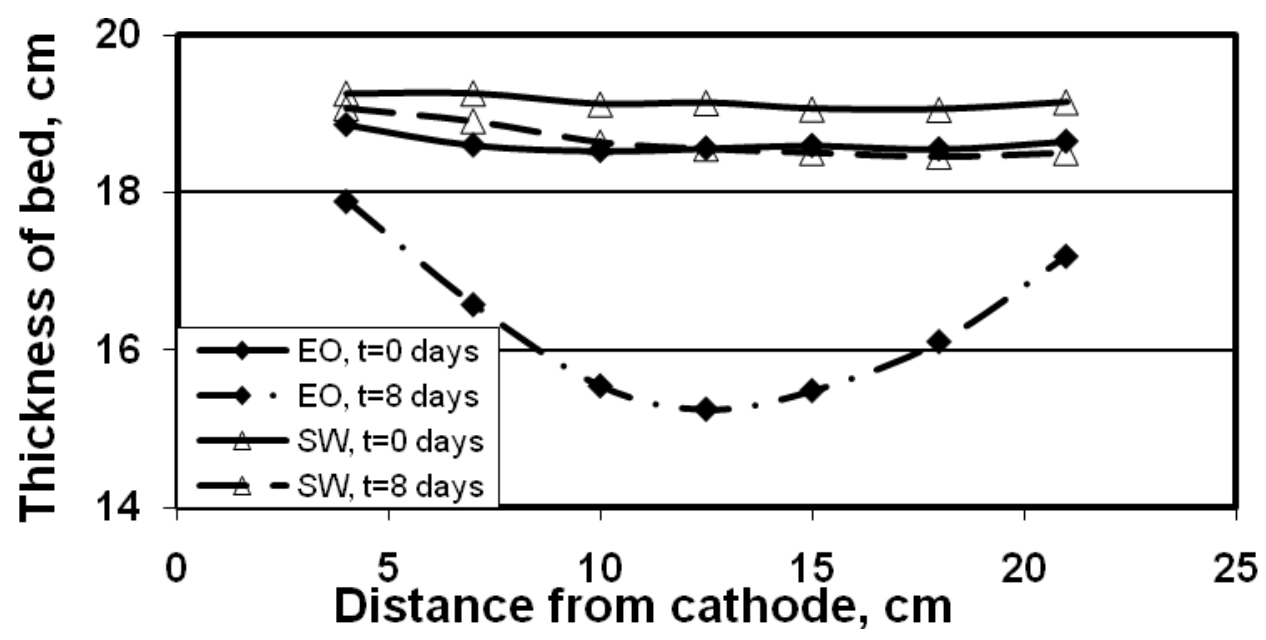

FIG. 2. Settlement profile of test beds

\section{Changes in Water Content}

The initial water contents, $w_{i}$, of the self weight consolidation and electro-osmotic consolidation test beds were $302 \%$ and $287 \%$, respectively. Efforts were made to keep the water contents of the test beds nearly the same. Compared to the average water content of $295 \%$, the difference in water content is less than $5 \%$. This small difference 
does not influence the comparison of the two tests significantly. The variation of average post consolidation water content, $w_{f-a v}$, along the test beds is shown in Figure 4. In the self weight consolidation test, the area near the drainage well exhibited a marginally higher reduction in water content due to shorter drainage path to the drainage well. Greater reduction in water content was observed in the electro-osmotic consolidation test bed, with the highest reduction occurring near the anode end. During electro-osmotic consolidation, water flows from the anode towards the cathode and accumulates at the cathode, hence causing a drier material near the anode compared to near cathode. In the self weight consolidation test, the water content decreased by only $1 \%$ at the end opposite to the drainage well. Whereas, in the electro-osmotic consolidation test the water content decreased by $32 \%$ near the corresponding anode end.

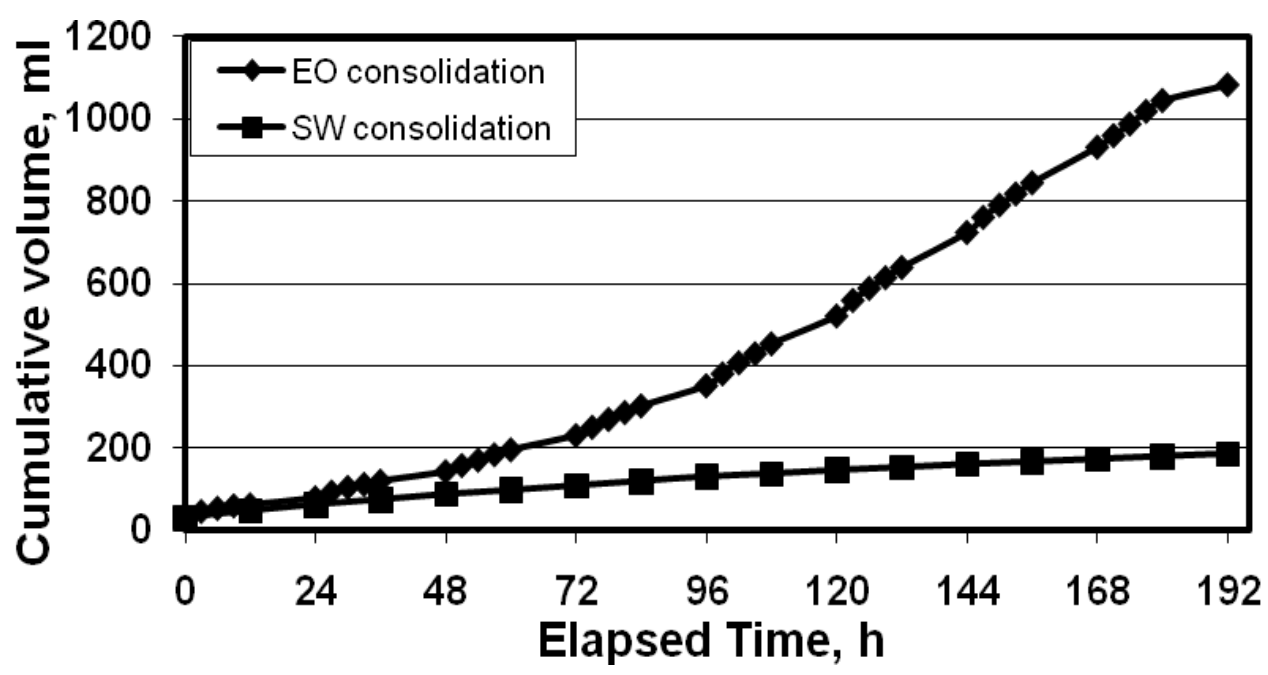

FIG. 3. Variation of total flow of water with time

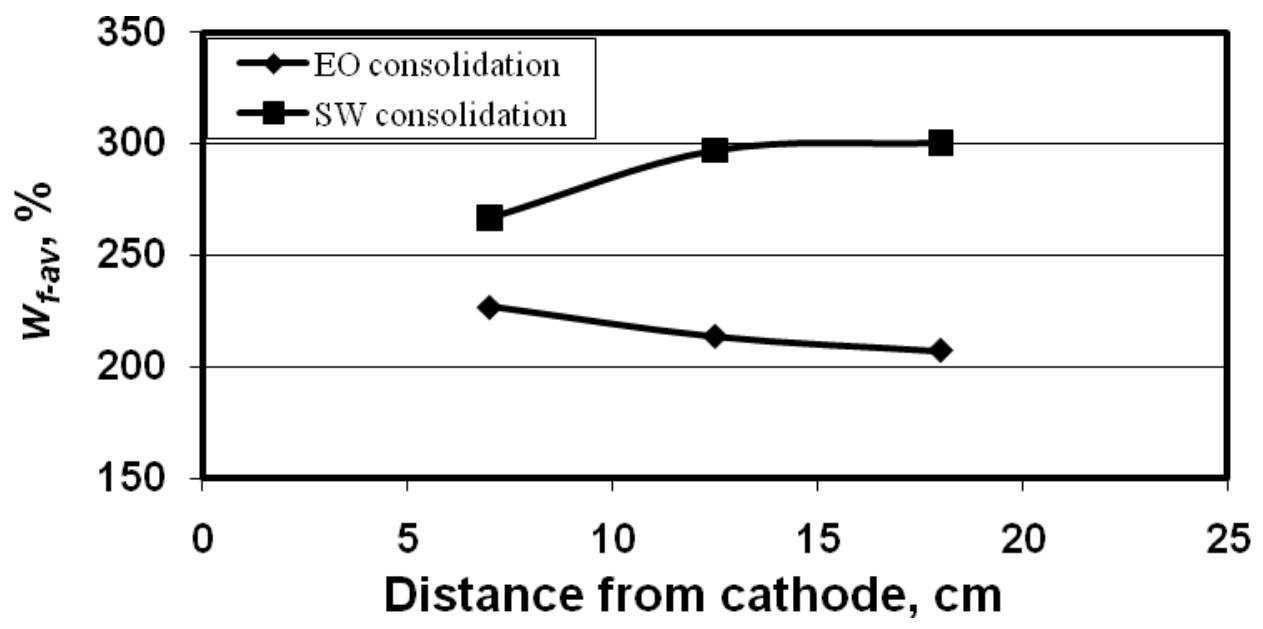

FIG. 4. Variation of average post-consolidation water content, $w_{f-a v}$, 


\section{Changes in Shear Strength}

Vane shear tests carried out at top and bottom of the test beds showed a significant improvement in shear strength in the electro-osmotic consolidation test bed. The initial undrained strength, $S_{u i}$, of the self weight consolidation and electro-osmotic consolidation test beds was $0.92 \mathrm{kPa}$. In the electro-osmotic consolidation test bed, the undrained strength near the anode end had increased to about $37 \mathrm{kPa}$. This is due to the lower water content and higher consolidation near the anode. On the other hand, the self weight consolidation test bed showed little improvement in strength at the end of the test. Figure 5 also shows the effect of disturbance on undrained strength. Remoulding due to disturbance caused significant reduction in the undrained strength of the electro-osmotically consolidated test bed.

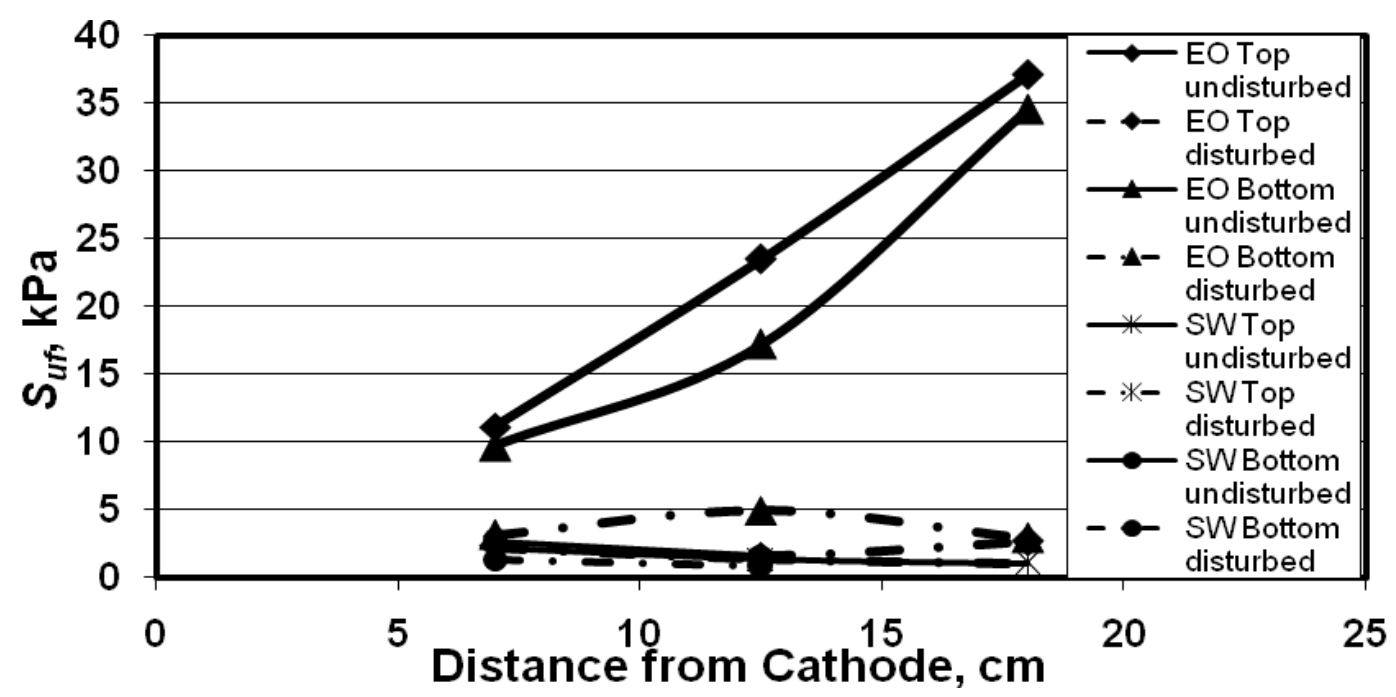

FIG. 5. Post-consolidation undrained strength, $S_{u f}$, at top and bottom of test bed

\section{Other Observations}

From the current and voltage measurements during the experiment, the power consumption was calculated approximately as $15 \mathrm{kWh} / \mathrm{m}^{3}$ for the 8 days of treatment. Water removal efficiency is defined as the ratio of difference in the initial and final water contents to the initial water content and expressed in percentage (Yuan \& Weng, 2003). For the electro-osmotic test, the water removal efficiency was $24.7 \%$, while for the self weight consolidation test it was only $4.6 \%$.

\section{CONCLUSIONS}

Based on the results of self weight consolidation and electro-osmotic consolidation tests, it is concluded that electro-osmosis was effective in the organic soil bed. Significant reduction in water content and increase in undrained strength were observed in the electro-osmosis treated organic soil bed. Electro-osmotic 
consolidation induced higher settlement in the test bed. Thus, surcharge material required to accelerate consolidation in the conventional preloading technique is not required in electro-osmotic consolidation. In the closed system of electro-osmotic consolidation, where water was not replaced at the anode, the area surrounding the anode underwent the highest improvement in strength.

\section{ACKNOWLEDGEMENTS}

The authors are grateful to Mr. R.S. Douglas, Emas Kiara Industries Bhd., Selangor, Malaysia, for providing the EVD for the experiments.

\section{REFERENCES}

Bergado, D.T., Balasubramaniam, A.S., Patawaran, M.A.B. and Kwunpreuk, W. (2000). "Electro-osmotic consolidation of soft Bangkok clay with prefabricated vertical drains." Ground Improvement, Vol. 4: 156-163.

Bergado, D.T., Sasanakul, I. and Horpibulsuk, S. (2003). "Electro-osmotic Consolidation of Soft Bangkok Clay Using Copper and Carbon Electrodes with PVD.” Geotechnical Testing Journal, Vol. 26 (3): 277-288.

Chew, S.H., Karunaratne, G.P., Kuma, V.M., Lim, L.H., Toh, M.L. and Hee, A.M. (2004). "A field trial for soft clay consolidation using electric vertical drains." Geotextiles and Geomembranes, Vol. 22: 17-35.

Fourie, A. B., Johns, D. G. and Jones, C. J. F. P. (2007). "Dewatering of mine tailings using electrokinetic geosynthetics”, Canadian Geotechnical Journal, Vol. 44, No. 2, 160-172.

Glendinning, S., Lamont-Black, J. and Jones, C. J. F. P. (2007). "Treatment of sewage sludge using electrokinetic geosynthetics", Journal of Hazardous Material, Vol. 139, No. 3, 491-499.

Glendinning, S., Lamont-Black, J. Jones, C.J.F.P. and Hall, J. (2008). "Treatment of lagooned sewage sludge in situ using electrokinetic geosynthetics." Geosynthetics International, Vol. 15 (3): 192-204.

Hamir, R.B., Jones, C.J.F.P. and Clarke, B.G. (2001). "Electrically conductive geosynthetics for consolidation and reinforced soil." Geotextiles and Geomembranes, Vol. 19: 455-482.

Kaniraj, S.R. and Huong, H.L. (2008). "Electro-osmotic consolidation experiments on North Sarawak peat", Indian Geotechnical Conference 2008, Bangalore, India, 7073.

Kaniraj, S.R. and Huong, H.L. (2009). "Electro-osmotic consolidation studies on peat of North Sarawak", Indian Geotechnical Conference 2009, Guntur, India, 455-458.

Shang, J.Q. (1998). "Two-dimensional electro-osmotic consolidation". Ground Improvement, 2: 17-25

Rittirong, A., Douglas, R.S., Shang, J.Q. and Lee, E.C. (2008). "Electrokinetic improvement of soft clay using electrical vertical drains." Geosynthetics International, Vol. 15 (5): 369-381.

Yuan, C. and Weng, C.H. (2003). "Sludge dewatering by electrokinetic technique: effect of processing time and potential gradient." Advances in Environmental Research, Vol. 7: 727-732. 